\title{
Model Pengembangan Kurikulum PAI Multikultural
}

\author{
Muslih Qomarudin, M.Pd. ${ }^{*}$ \\ ${ }^{1}$ STIT Al- Hikmah Pisang Baru \\ *E-mail: muslihqomarudin@gmail.com
}

\begin{abstract}
Abstrak
Pendidikan agama Islam memberi kontribusi sangat besar dalam membangun karakter dan peradaban bangsa yang bermartabat. Oleh karena itu dibutuhkan pembelajaran pendidikan agama Islam yang kontruktif dan kontektual, sehingga keberhasilan penyelenggaraan pendidikan agama berkontribusi terhadap calon generasi yang kaffah. Sebaliknya, kegagalan dalam penyelenggaraan pendidikan agama akan berdampak terhadap lemahnya akhlak generasi penerus dimasa mendatang dan akhirnya akan meruntuhkan Akhlak dan peradapan bangsa. Latar belakang budaya yang beragam di indonesia mengharuskan kurikulum PAl memiliki model kurikulum yang menghadirkan pendidikan yang toleran. Model pembelajaran PAI Multikultural yang mendasarkan keberagaman budaya menjadi dasar dalam pengembangan kurikulum PAI. Pengembangan kurikulum PAI multikultural menjadi pilar kelestarian budaya daerah dan budaya Nasional.
\end{abstract}

Kata kunci: Model, Pengembangan Kurikulum PAI dan Multikultural.

\section{PENDAHULUAN}

Kemajemukan dan keragaman budaya bangsa bukan menjadi hambatan dalam proses memanusiakan manusia yang beradab. Kemajemukan dan keragaman budaya menjadi simbol dan kekuatan bangsa untuk mengeksporasi perbedaan sebagai rahmat bagi semesta alam. Pendidikan Agama Islam sebagai kurikulum perlu menghadirkan model kurikulum yang dapat mewujudkan pendidikan yang mampu menumbuhkan sikap toleran sehingga timbul pengakuan terhadap kebudayaan yang beraneka ragam sehingga mewujudkan pendidikan yang memberikan pengakuan, penghargaan dan penghormatan terhadap perbedaan dan kesetaraan baik ras, bahasa, suku, budaya dan agama. Model pengembangan kurikulum PAI yang dapat ditawarkan yaitu kurikulum PAI Multikultural.

\section{METODE/EKSPERIMEN}

Jenis Penelitian yang digunakan adalah penelitian pustaka murni dan pendekatan kualitatif bersifat deskriptif, peneliti menggambarkan, mengungkapkan dan menjelaskan bagaimana Pengembangan kurikulum PAI multikultural . pengumpulan data yang digunakan adalah dokumentasi atau studi dokumen. Analisa data berupa kajian isi untuk menarik kesimpulan yang sahih dari buku/dokumen.

\section{HASIL DAN PEMBAHASAN}

\section{A. PENGERTIAN PENDIDIKAN MULTIKULTURAL}

Pendidikan sangat sentral peranannya dalam menanggulangi akses negatif dari perkembangan zaman. kurikulum adalah salah satu aspek penting dalam pendidikan yang mempunyai peran signifkan menentukan kemajuan peradaban serta menjawab tantangan kehidupan. merekonstruksi kurikulum yang ada sebagai salah satu lembaga pendidikan Islam yang berkualitas dengan inovasi model-model pengembangan kurikulum yang relevan dengan isu-isu globalisasi.(Marlina \& Iswati, 2018) 
Menurut Andersen dan Cusher, pendidikan multikultural dapat diartikan sebagai pendidikan mengenai keragaman kebudayaan. Sedang James Banks, mendefinisikan pendidikan multikuitural sebagai pendidikan untuk people of color. Artinya, pendidikan multikultural ingin mengeksplorasi perbedaan sebagai keniscayaan (anugrah tuhan /sunatullah). Tidak jauh berbeda, Azra menjelaskan pendidikan multikultural sebagai pengganti dari pendidikan interkultural diharapkan dapat menumbuhkan sikap peduli dan mau mengerti atau adanya politik pengakuan terhadap kebudayaan kelompok manusia, seperti toleransi, perbedaan etno-kultural dan agama, diskriminasi, HAM, demokrasi dan pluralitas, kemanusiaan universal, serta subyek-subyek lain yang relevan.(Irsad, 2016) Pendidikan multikultural ialah pendidikan yang memberikan pengakuan, penghargaan dan penghormatan terhadap perbedaan dalam kesetaraan baik bahasa, ras, suku, budaya dan agama.

\section{B. NILAI-NILAI PENDIDIKAN AGAMA ISLAM MULTIKULTURAL}

Menurut Yaya Suryana dan A. Rusdiana, nilai-nilai pendidikan Islam berbasis multikultural yaitu: 1. Nilai Andragogi; 2. Nilai Perdamaian; 3. Nilai Inklusivisme; 4. Nilai Kearifan; 5. Nilai Toleransi; 6. Nilai Humanisme; 7. Nilai Kebebasan.(Suryana, Yaya dan A.Rusdiana;2015) . Sedangkan Muhammad Tholhah Hasan, mengatakan bahwa "Ta'aruf " (saling kenal) merupakan indikasi positif dalam suatu masyarakat plural untuk dapat hidup bersama, saling menghormati dan saling menerima perbedaan yang ada diantara mereka. Ta'aruf menjadi gerbang yang member akses melakukan langkah-langkah berikutnya dalam membangun kebersamaan kehidupan kultural, melalui karakterkarakter inklusif seperti "tasamuh" (toleransi), "tawassuth" (moderat), "ta'awun" (tolong menolong), "tawazun" (harmoni). Hal-hal tersebut kami sebut sebagai akar-akar nilai inklusif dari Multikulturalisme Islam. (Hasan, Muhammad Tholchah:2016)

\section{TIGA PRINSIP PENYUSUNAN PROGRAM PENDIDIKAN MULTIKULTURAL}

H.A.R. Tilaar menuturkan tiga prinsip pokok program dalam pendidikan multikultural, yaitu: ( Tilaar, H.A.R. 2004)

1. Pendidikan multikultural didasarkan kepada pedagogik baru yaitu pdagogik yang dasarkan kesetaraan manusia (equity pedagogy). Pedadgogik kesetaraan bukan hanya mengakui akan hak asasi manusia tetapi juga hak kelompok, kelompok suku bangsa, kelompok bangsa untuk hidup berdasarkan kebudayaannya sendiri.

2. Pendidikan multikultural ditujukan kepada terwujudnya manusia Indonesia cerdas. Pendidikan multikultural diarahkan untuk mengembangkan pribadi-pribadi manusia Indonesia agar menjadi manusiamanusia yang cerdas.

3. Prinsip globalisasi. Globalisasi tidak dapat kita bendung karena persoalaanya adalah bagaimana kita memanfaatkan arus globalisasi tersebut. Globalisasi tidak perlu kita takuti apabila kita mengetahui arah serta nilai-nilai baik dan/atau buruk yang dibawanya.

\section{PENGEMBANGAN KURIKULUM PAI MULTIKULTURAL}

Pengembangan kurikulum pendidikan multikultural mendasarkan prinsip bahwa keragaman budaya menjadi dasar dalam menentukan filsafat, teori, model, dan pengembangan komponen kurikulum, serta kurikulum berperan sebagai media pengembangan kebudayaan daerah dan nasional. Sehingga kebudayaan daerah yang beragam bisa terus lestari dan berkembang serta menjadi pilar-pilar penyangga kebudayaan nasional. Pengembangan kurikulum dengan pendekatan multikultural dapat dilakukan berdasarkan langkah-langkah:

1. Mengubah filosofis kurikulum dari yang berlaku seragam seperti saat ini kepadafilosofis yang lebih sesuai dengan tujuan, misi, dan fungsi setiap jenjang pendidikan dan unit pendidikan.

2. Teori kurikulum tentang konten (curriculum content), harus berubah dari teori yang mengartikan konten sebagai aspek substantif yang berisikan fakta, teori, generalisasi ke pengertian yang mencakup nilai moral, prosedur, proses dan ketrampilan (skills).

3. Teori belajar yang digunakan dalam kurikulum masa depan yang memerhatikan keragaman 
sosial, budaya, ekonomi, dan politik tidak boleh lagi hanya mendasarkan diri pada teori psikologi belajar yang menempatkan siswa sebagai makhluk sosial, budaya, politik yang hidup sebagai anggota aktif masyarakat, bangsa, dan dunia yang harus diseragamkan oleh instiyusi pendidikan.

4. Proses belajar yang dikembangkan untuk siswa haruslah berdasarkan proses yang memiliki tingkat isomorphisme yang tinggi dengan kenyataan sosial. Evaluasi yang digunakan haruslah meliputi keseluruhan aspek kemampuan dan kepribadian siswa sesuai dengan tujuan dan konten yang dikembangkan (Mahfud, 2014:222-224).

Adapun pengembangan model pembelajaran multikultural didasarkan pada prinsip dasar, yaitu:(Nuryanti, 2008, p. 335)

1. Pengenalan Jati Diri

Pendidikan multikultural harus dimulai dari pengenalan terhadap jati diri sendiri, bukan jati diri etnik lain

2. Mengembangkan Sikap Non-Etnosentis

Pendidikan multikultural hendaknya dikembangkan agar pembelajar tidak mengembangkan sikap etnosentris.

3. Pengembangan secara Integratif

Komprehensif dan Konseptual Pendidikan multikultural seharusnya dikembangkan secara integratif komprhensif dan konseptual agar kurikulum menginkooperasi sebuah kurikulum yang bersifat total.

4. Menghasilkan Sebuah Perubahan

Pendidikan multikultural harus menghasilakan perubahan, tidak hanya pada materi kurikulum tetapi juga pada praktik pembelajaran dan struktur social dari sebuah kelas.

5. Menekankan Aspek Afektif dan Kognitif

Pendidikan multikultural lebih menekankan aspek afektif dan kognitif dengan cara mengaitkan masalah keseharian yang dihadapi siswa di lingkungan sempit ataupun luasnya.

6. Kontektual

Pendidikan multikultural harus mencakup realita sosial dan kesejarahan dari etnit-etnik dan bangsa Indonesia. Kontektualisasi pendidikan multicultural harus bersifat lokal, nasional, dan global.

Pengembangan kurikulum PAI multikuktural merupakan salah satu model pengembangan kurikulum PAI yang dapat diwujudkan, yang pada prinsip pengembangannya berupa pengenalan jati diri, mengembangkan sikap non-etnosentis, pengembangan secara integratif komprehensif dan konseptual, menghasilkan sebuah perubahan, menekankan aspek kognitif dan afektif, dan kontekstual.

\section{PENUTUP}

Pendidikan agama Islam memberi kontribusi sangat besar dalam membangun karakter dan peradaban bangsa yang bermartabat. Latar belakang budaya yang beragam di indonesia mengharuskan kurikulum PAI memiliki model kurikulum yang menghadirkan pendidikan yang toleran. Model pembelajaran PAI Multikultural yang mendasarkan keberagaman budaya menjadi dasar dalam pengembangan kurikulum PAI. Pengembangan kurikulum PAI multikultural menjadi pilar kelestarian budaya daerah dan budaya Nasional.

\section{UCAPAN TERIMAKASIH}

Ucapan terimakasih ditujukan kepada STIT AL Hikmah Pisang Baru yang memberi kontribusi penyelesaian artikel ini dan Pengelola Jurnal Al l'tibar atas terpublikasinya artikel ini. 


\section{DAFTAR PUSTAKA}

Irsad, M. (2016). PENGEMBANGAN KURIKULUM PENDIDIKAN AGAMA ISLAM DI MADRASAH (Studi Atas Pemikiran Muhaimin). Iqra', 2(1), 231-267.

Marlina, M., \& Iswati, I. (2018). Pengembangan Kurikulum PTAI Menghadapi Masyarakat Ekonomi ASEAN (MEA). Al-l'tibar : Jurnal Pendidikan Islam, 5(1), 1-9.

https://doi.org/10.30599/jpia.v5i1.305

Nuryanti. (2008). FILSAFAT PENDIDIKAN ISLAM TENTANG KURIKULUM Nuryanti. 5, No.3, 329338.

Hasan, Muhammad Tholchah, (2016). Pendidikan Multikultural Sebagai Opsi Penanggulangan Radikalisme, (Malang:Unisma).

Suryana, Yaya dan A.Rusdiana, (2015). Pendidikan Multikultural : Suatu Upaya Penguatan Jati Diri Bangsa, (Bandung:Pustaka Setia).

Tilaar, H.A.R.. Multikulturalisme: (2004). Tantangan-tantangan Global Masa Depan dalam Transformasi Pendidikan Nasional. (Jakarta: Grasind). 